\title{
A GRANULATION TUMOUR OF THE CONJUNCTIVA*
}

BY

\author{
Surgeon Lieut.-Commander J. D. J. FREEMAN \\ R.N.V.R.
}

A SERGEANT of Royal Marines first came under my care on October 1, 1942, when he was admitted to a Royal Naval Hospital. At this timè he was thirty years of age and in splendid physical condition, standing well over six feet. He was complaining of trouble with his left eye. The upper lid felt heavy and dropped and the eye tended to water, especially towards the end of the day. There was no actual pain, but constant discomfort. The eye-had first become troublesome in 1933 or 1934, when he was stationed in West and South Africa. Discomfort had gradually become more marked. The right eye had never been affected.

On examination he was found to have a slight degree of ptosis, but the pupil was not covered. The conjunctiva covering the tarsal plate of the left upper lid was seen to be covered with multiple pinkish granulomatous nodules; glistening and soft in consistency. Some of the nodules were quite large and yellow in colour, especially towards the upper limit of the tarsus. There was no ropy discharge or milky film over the area. The conjunctiva above the upper limit of the tarsus appeared unaffected. There was some scarring as a result of curetting of the conjunctiva and the removal of specimens of tissue for biopsy. Careful examination of the cornea with loupe and slit-lamp revealed no signs of pannus. The bulbar conjunctiva and the lower fornix appeared quite healthy. The pre-auricular gland was not enlarged. The right eye was unaffected, the upper fornix appearing quite healthy.

At first treatment consisted of copper sulphate drops twice daily combined with a painting of the upper lid with the copper sulphate stick. This succeeded in reducing the discomfort somewhat. A fortnight later, at the suggestion of Mr. F. A. Williamson-Noble, Consultant Oculist to the Royal Navy, the treatment was changed. The eye was now irrigated three times a day with a half-saturated magnesium sulphate solution, and half an hour after each irrigation one drop of 30 per cent. albucid was instilled. A search for a septic focus proved negative. The blood sedimentation rate and.blood count were normal, though there was a relative lymphocytosis. On October 23, 1942, a course of injections of old tuberculin was instituted, starting with 0.00001 c.c. and working up to a dose of 1.0c.c., fifteen injection's in all being given. On

* Received for publication, January 16, 1944. 
November 15 he was discharged to out-patients and continued with the copper sulphate drops and gutt. albucid 30 per cent. Early in the New Year he visited Gloucester on leave, and while there Mr. W. Niccol very kindly examined his eye. He thought that there was a possibility of a new growth of the Meibomian glands, and suggested excision of the affected area or the application of radium. As excision seemed quite feasible, the patient was admitted to the ward again, and on March 17, 1943, left upper tarsectomy was performed by Wheeler's method. This proved very successful, as all the diseased tissue was removed, the slight ptosis cured, and the patient had no further discomfort. He made an uneventful recovery, and was discharged on March 24.

$\mathrm{Mr}$. Eugene. Wolff very kindly carried out a microscopical examination of the disease tissue, and his report was as follows :"The Meibomian glands appear to be intact : the affected tissue goes down to the tarsal plate. It consists of a mass of granulation tissue much like that found in a typical granulation tumour of the conjunctiva. The conjunctiva is largely exfoliated, but in - places sends in gland-like processes, some of which have dilated into cysts. There is no evidence of a new growth. The condition might have arisen from cauterisation which destroyed the conjunctiva, which was later replaced by granulation tissue."

There seem to be three main causes that could have given rise to this condition-trachoma, tuberculosis, or vernal catarrh. Parinaud's conjunctivitis was negatived by the absence of any involvement of the pre-auricular lymph gland. Trachoma appears to be unlikely, as, in spite of the long history, careful examination with the slit-lamp did not reveal any corneal involvement. Against spring catarrh are the facts that the condition was unilateral, that there were no periods of freedom from discomfort, and the length of the history. Microscopical examination failed to reveal the presence of the tubercle bacillus, and the course of tuberculin injections did not give rise to any improvement in the condition:

It seems worth recording this case in view of the very interesting case described by $\mathrm{Mr}$. A. F. MacCallan in the Transactions of the Ophthalmological Society of the United Kirigdom for 1942 . Mr. MacCallan's case showed a more extensive involvement of the conjunctiva, including the bulbar conjunctiva. The two cases, however, seem to have many points of similarity. Presumably radium therapy would have resulted in an equally excellent result as Mr. MacCallan obtained.

I should like to express my gratitude to $\mathrm{Mr}$. Williamson-Noble, Mr. Niccol, and Mr. Eugene Wolff for their valuable help in this case and to the Admiralty for permission to publish the report. 